\title{
Influence of sea surface winds on shearwater migration detours
}

\author{
Jacob González-Solís ${ }^{1, *}$, Angel Felicísimo², James W. Fox ${ }^{3}$, Vsevolod Afanasyev ${ }^{3}$, \\ Yann Kolbeinsson ${ }^{4}$, Jesús Muñoz ${ }^{5}$
}

\author{
${ }^{1}$ Departament de Biologia Animal (Vertebrats), Universitat de Barcelona, Av Diagonal 645, 08028 Barcelona, Spain \\ ${ }^{2}$ Escuela Politécnica, Universidad de Extremadura, 10071 Cáceres, Spain \\ ${ }^{3}$ British Antarctic Survey, High Cross, Madingley Road, Cambridge CB3 0ET, UK \\ ${ }^{4}$ South Iceland Nature Centre, Strandvegur 50, 900 Vestmannaeyjar, Iceland \\ ${ }^{5}$ Real Jardín Botánico, CSIC, Plaza de Murillo 2, 28014 Madrid, Spain
}

\begin{abstract}
To test the potential effects of winds on the migratory detours of shearwaters, transequatorial migrations of 3 shearwaters, the Manx Puffinus puffinus, the Cory's Calonectris diomedea, and the Cape Verde $C$. edwardsii shearwaters were tracked using geolocators. Concurrent data on the direction and strength of winds were obtained from the NASA SeaWinds scatterometer to calculate daily impedance models reflecting the resistance of sea surface winds to the shearwater movements. From these models we estimated relative wind-mediated costs for the observed synthesis pathway obtained from tracked birds, for the shortest distance pathway and for other simulated alternative pathways for every day of the migration period. We also estimated daily trajectories of the minimum cost pathway and compared distance and relative costs of all pathways. Shearwaters followed 26 to $52 \%$ longer pathways than the shortest distance path. In general, estimated wind-mediated costs of both observed synthesis and simulated alternative pathways were strongly dependent on the date of departure. Costs of observed synthesis pathways were about $15 \%$ greater than the synthesis pathway with the minimum cost, but, in the Cory's and the Cape Verde shearwaters, these pathways were on average 15 to $20 \%$ shorter in distance, suggesting the extra costs of the observed pathways are compensated by saving about 2 travelling days. In Manx shearwaters, however, the distance of the observed synthesis pathway was $25 \%$ longer than that of the lowest cost synthesis pathway, probably because birds avoided shorter but potentially more turbulent pathways. Our results suggest that winds are a major determinant of the migratory routes of seabirds.
\end{abstract}

KEY WORDS: Migration costs $\cdot$ Wind influence $\cdot$ Bird flight $\cdot$ Shearwaters $\cdot$ Global location sensing GLS · Geolocator

Resale or republication not permitted without written consent of the publisher

\section{INTRODUCTION}

Migration is a major activity in the life of many seabird species. Twice a year millions of shearwaters travel 10s of 1000 s of kilometres across the equator to move between wintering and breeding areas. Ringing programmes, land-based observers and observations at sea have provided some information on broad-scale migration corridors (Serventy 1953, Alerstam 1990, Brooke 1990, Spear \& Ainley 1999, Camphuysen \& Van Der Meer 2001). These studies have suggested a figure-eight pattern, clockwise in the northern and counter-clockwise in the southern hemisphere, but detailed migration pathways remain largely unknown. Currently, tracking devices provide invaluable information on spatial and temporal aspects of the migration at an individual level (Shaffer et al. 2006, González-Solís et al. 2007). These studies have confirmed that shearwaters often do not travel the shortest distance between breeding and wintering areas, but may take longer pathways than expected. Furthermore, the figure-eight pattern of annual movements 
has been confirmed for sooty shearwaters Puffinus griseus in the Pacific Ocean (Shaffer et al. 2006). Understanding why shearwaters follow detours in their transequatorial movement is essential in predicting the spatio-temporal passage of shearwaters and will be crucial in defining the main seabird corridors for conservation purposes. Investigating the principles determining migratory detours has been a prime issue in optimal migration studies (Alerstam 2001, Erni et al. 2005). In this regard 2 main currencies have been proposed to be optimised in a migration episode, time and energy (Alerstam \& Lindström 1990). Minimising the energy cost of transport may be advantageous because the energy saved can be crucial if food resources or fat reserves are scarce, or it can just be invested in more rewarding activities. Minimising time may compensate potentially greater costs because arriving earlier to the breeding or wintering grounds than other competitors may be advantageous.

One major factor influencing the cost of bird migration is wind conditions (Alerstam 1979, Pennycuick 1982, Richardson 1990, Liechti \& Bruderer 1998, Gauthreaux et al. 2004, Liechti 2006). Wind speed can achieve similar values to those of flying birds, and therefore ground speed can be substantially increased or decreased depending on the wind direction with respect to bird heading. This is also true in shearwaters and fulmars, which rely on mixed flap and gliding flight utilising wave uplift and dynamic soaring, both very dependent on the strength of the winds (Alerstam et al. 1993, Furness \& Bryant 1996, Rosén \& Hedenström 2001). Indeed, several studies have shown shearwaters often follow prevailing winds, during both migration and foraging movements, suggesting that birds optimise the use of winds for gliding (Shaffer et al. 2006, González-Solís et al. 2007, Navarro \& GonzálezSolís 2009). When taking into account the costs imposed by winds, the fastest and the shortest distance pathways may not be the same. Shortest pathways, e.g. between breeding and wintering grounds, may be more costly in unfavourable winds. On the contrary, apparently low-cost pathways, e.g. high wind speed in the direction of travel, may save energy, but can be much further.

So far, evidence of wind effects on migrating seabirds has been mainly inferred from local observations and synoptic weather maps (Pennycuick 1982, Alerstam et al. 1993, Nicholls et al. 1997, Spruzen \& Woehler 2002, Murray et al. 2003). Although this is the best approach when working at detailed scales, remote-sensing data make it possible to work at broader scales, using concurrent information from winds and migration paths to analyse the responses of birds to wind conditions (Felicísimo et al. 2008). Strength and direction data on sea surface winds are now available from satellite scatterometers with high spatial and temporal resolution and global coverage. Shearwaters fly low over the sea surface, and therefore information on sea surface winds can be used to build anisotropic 'cost models'. Anisotropic cost analysis is a procedure to estimate the minimum accumulative cost of travelling from a source cell to every other cell on a raster model, which must be considered as a friction surface. Azimuth and speed, the 2 components of a wind vector, are used in the cost calculations. In the case of the azimuth, the minimum resistance to the movement corresponds to the exact wind vector azimuth. Deviations from the actual wind azimuth are penalised through a function in proportion to angle deviation. Regarding wind speed, it enters into the model as a resistance factor; therefore, tail winds reduce cost, while head winds increase it. Using data on wind conditions over the studied migration period, it is possible to calculate the lowest wind resistance pathway connecting specific wintering and breeding areas, which should reasonably reflect the lowest wind-mediated cost pathway for the birds. Pathways with the lowest wind cost can then be compared to the observed pathways followed by the tracked birds. This approach was used to analyse the postnuptial migration of Cory's shearwaters breeding in the northern hemisphere and wintering in the Benguela system (Felicísimo et al. 2008). In the aforementioned study, the authors found that tracked shearwater pathways were very similar to the lowest cost pathway predicted from the analysis of wind conditions experienced by birds during their migration period. However, the suitability of alternative low cost pathways and the time required to travel along the alternative pathways was not considered.

Most optimality models used to understand bird migration have focused on passerines, and they generally obtain predictions assuming either minimisation of total migration time or minimisation of energy. Some recent theoretical approaches have taken both currencies into account, but the inability to track small passerines prevents testing their predictions (Houston 1998, Vrugt et al. 2007). In the present paper, a simple optimality approach is developed relating both potentially conflicting currencies to understand the actual pathway choice made by the shearwaters during migration. Specifically, we tested whether the assistance of sea surface winds makes migration pathways, although of longer distance, less costly (as indicated by less wind resistance) to birds than shorter pathways. Migration routes of 3 Atlantic shearwater species, the Manx shearwater Puffinus puffinus, the Cory's shearwater Calonectris diomedea, and the Cape Verde shearwater $C$. edwardsii were tracked using geolocators. The migration routes in which the observed path- 
ways clearly differed from the shortest path between breeding and wintering grounds were selected for analysis. We also calculated the wind cost of intermediate simulated pathways, including the observed synthesis pathway used by the shearwaters and the synthesis of the daily minimum cost pathways. Finally, we compared the choice made by shearwaters in relation to the simulated pathways with differing costs and distances, in order to understand the dominating factor explaining the pathway choice made by shearwaters.

\section{MATERIALS AND METHODS}

Bird tracking and migration pathways. In May and June 2006, we deployed a total of 20 geolocators on Manx Puffinus puffinus shearwaters at Heimaey (Iceland). After approximately 1 yr, we recovered data from 10 geolocators. For this study, we use the last portion of 8 prenuptial trajectories, from the Intertropical Convergence Zone to Iceland. In June and July 2002, we deployed a total of 50 light level geolocators on Cory's Calonectris diomedia shearwaters breeding at Vila Islet (Azores), Veneguera (Gran Canaria, Canary Islands) and Pantaleu Islet (Balearic Islands, Mediterranean). After 1 or $2 \mathrm{yr}$, we recovered data from 27 geolocators. For this study, we use the postnuptial migration of 20 transequatorial trajectories starting in the Canary Current system. In July 2006, we deployed a total of 40 geolocators on Cape Verde C. edwardsii shearwaters at Raso and Curral Velho Islets (Cape Verde). After approximately 1 yr, we recovered complete data from 26 geolocators. For this study, we use 25 prenuptial trajectories from the wintering area (the Brazil and Falklands/Malvinas confluence in front of the Uruguay coast) to Cape Verde.

For the purpose of the present study, we selected migration routes showing detours that allowed us to contrast the hypothesis of long distance detour pathways versus the shortest pathway. Migration routes in which the shortest path did not differ from the observed path were not considered, as they would not allow contrasting of the 2 hypotheses. Synthesis pathways were calculated through a kernel density estimation with the 'linedensity' command on an ArcInfo Workstation 9.1. Alternative pathways to contrast our hypothesis were extrapolated as alternative possibilities between the shortest and the observed pathways, as were similar but intermediate or more extreme detours than the observed pathways.

Birds were tracked using 5 to $10 \mathrm{~g}$ geolocators developed by the British Antarctic Survey (BAS; Afanasyev 2004). It has been shown that $10 \mathrm{~g}$ geolocators on Cory's shearwaters have no detectable short-term effects on the birds (Igual et al. 2005). We deployed them on the leg of each bird, mounted on a DARVIC ring. The geolocators had an internal clock and measured the light levels every $1 \mathrm{~min}$, recording the maximum reading within each 10 min interval (Afanasyev 2004). From this information, 2 positions per day (one corresponding to midday and the other to midnight) can be inferred with an average $( \pm \mathrm{SD})$ accuracy of $186 \pm 114$ km (Phillips et al. 2004). Positions were calculated using BAS software by inspecting the integrity of the light curve day by day and fitting dawn and dusk times. To filter unrealistic positions we removed (1) those obtained from light curves showing interferences at dawn or dusk (mainly due to the bird staying in the burrow); (2) those with a speed index $>90 \mathrm{~km} \mathrm{~h}^{-1}$, as calculated by the root of the square speed average of the segments formed with the 2 preceding and the 2 following positions; (3) those within the equinox periods; and (4) those on land areas.

Wind data. We used free data from SeaWinds on QuikSCAT scatterometer, an instrument developed by NASA JPL (J. P. Laboratory 2001), to measure the speed and direction of ocean surface winds. The QuikSCAT satellite was launched into a sun-synchronous, 803 km, circular orbit on 19 June 1999. The SeaWinds instrument is a specialised microwave radar (scatterometer) that measures near-surface wind speed and direction over the Earth's oceans (J. P. Laboratory 2001). Data are not gathered for the whole ocean surface every day, and, although unobstructed by clouds, measurements are affected by rain. To avoid areas without satellite data and to reduce rain contamination, we calculated wind speed and azimuth daily as the average of that day, the following and the preceding day.

The QuikSCAT HDF (hierarchical data format) files contained a set of 16 scientific data sets (SDS). A HDF SDS is a fixed dimensional array. The QuikSCAT SDS uses a simple $0.25^{\circ}$ rectangular latitude to longitude grid that contains 1440 pixels from east to west and 720 pixels from south to north in a standard 'plate carrée' projection. The data used in our study included daily data from January 2002 to December 2007, corresponding to the periods matching the analysed migration trajectories. Wind data were obtained from PO-DAAC (Physical Oceanography Distributed Active Archive Center).

Anisotropic cost analysis. To calculate the cost of travelling over the ocean surface in relation to wind conditions we used an anisotropic cost analysis to create a friction surface. This surface is a grid where the cost to move over each pixel depends on the angle between the movement heading and the azimuth wind, as well as the wind speed, i.e. we used the cost to mean resistance of wind to the movement of the birds, 
which we assumed to reflect the energetic costs of the birds to move among pixels.

To model the variation in wind resistance as an estimate of the energy expenditure suffered by a bird in the open ocean in relation to the wind azimuth, we used a cost function inferred from an experimental study on flying albatrosses (Weimerskirch et al. 2000). These authors recorded heart rates of flying albatrosses as an instantaneous index of energy expenditure in relation to wind direction. Although albatrosses may show some slight differences in flight behaviour compared to shearwaters, to our knowledge this is the only available experimental data about the influence of winds on the energy expenditure of a Procellariiform. In our inferred cost function, to calculate the cost to move over a pixel, speed was not considered as an isolated element, but in conjunction with the angle between wind and movement vectors: tail winds were considered a help, and head winds, an obstacle to movement, both proportionally to absolute speed $\left(\mathrm{m} \mathrm{s}^{-1}\right)$ (Fig. 1). In the absence of wind, the cost of moving through the friction surface was set to 31 (arbitrary units) and was held constant with respect to the movement heading (i.e. winds not helping or hindering the movement). In the case of movement following the exact wind vector azimuth (tail wind corresponding to $0^{\circ}$ between vector flight and vector wind) and maximum wind speed (30 $\mathrm{m} \mathrm{s}^{-1}$ as defined by the sensitivity of the QuikSCAT), we assigned the minimum resistance value of 1 (arbitrary units). Deviations from this minimum cost angle and/or decrease in wind speed were increasingly costly until reaching a maximum of 61 (arbitrary units) at an angle of $180^{\circ}$ (head wind, opposite to bird flight) and a wind speed of $30 \mathrm{~m} \mathrm{~s}^{-1}$ (Fig. 1).

An iterative procedure on a cell-by-cell basis from any given source to final points allows the estimation of the accumulated cost of simulated trajectories over the friction surface, as well as the definition of the theoretical minimum cost path between the predefined source and final points. Cost calculations are based on friction surfaces, where the value of each pixel corresponds to the cumulative cost to travel from the origin to that pixel for each day. Cost surfaces were calculated for each day using daily wind conditions during the migration period and year of the tracked birds. Source and final points were set as the breeding colony positions or the core position of a kernel analysis on routes or in wintering areas of the tracked birds. Once the source and the final points and the daily cost surfaces

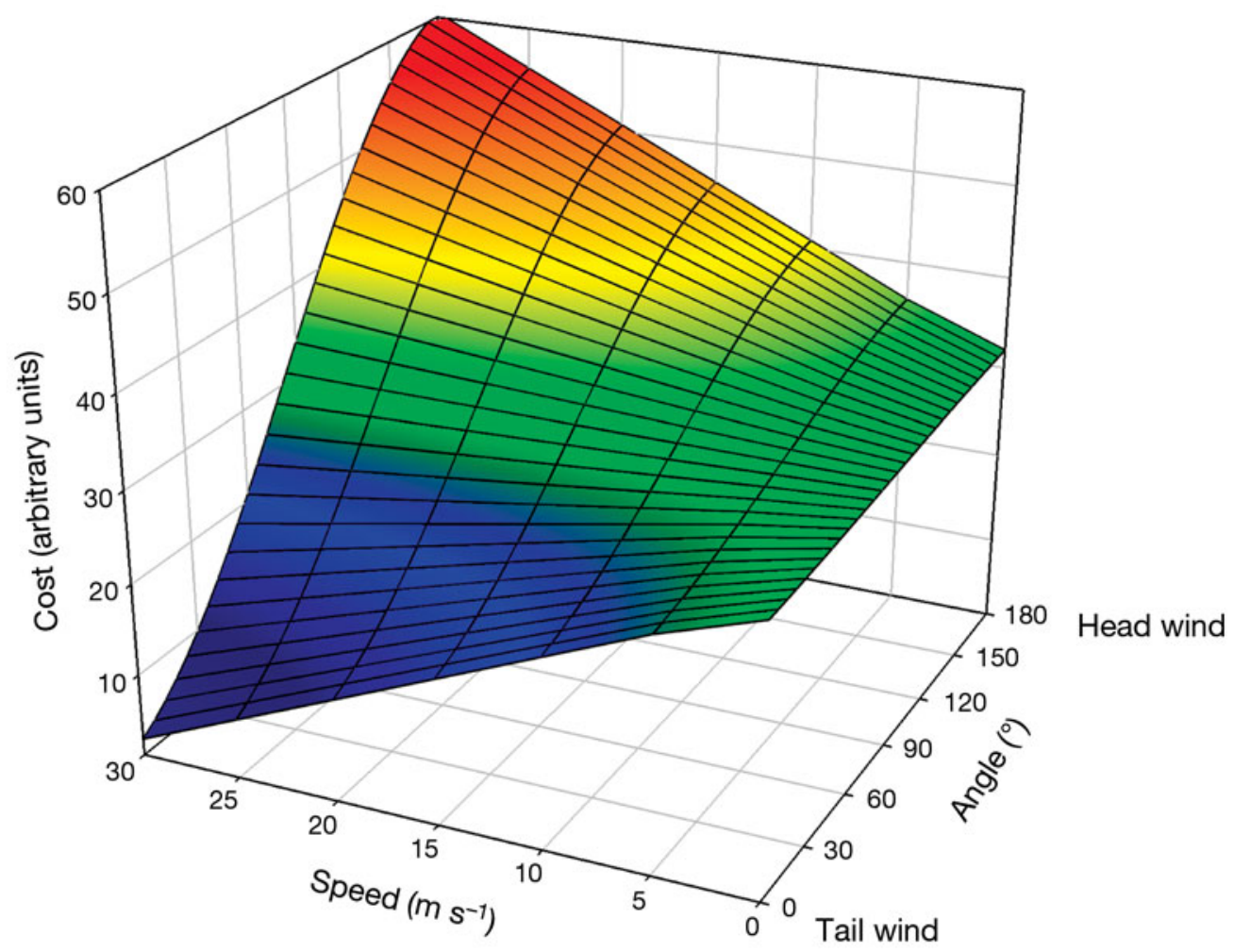

Fig. 1. Cost function used to calculate the cost (arbitrary units) to move over a friction surface depending on wind speed ( $\mathrm{m} \mathrm{s}^{-1}$ ) and the angle between the bird heading and the wind azimuth (in degrees). The travelling cost to move over the friction surface in the absence of wind was set at 31 (green); travelling cost decreases with faster tail winds down to 1 (deep blue) and increases with faster head winds up to 61 (red) 
corresponding to the migration period were defined, we calculated (1) daily costs for the observed synthesis pathway (obtained from the actual trajectories followed by the tracked birds), (2) daily costs for each simulated alternative path and (3) a synthesis of the daily minimum cost pathways. Based on the daily cost estimations, we then calculated the mean cumulative cost for the whole period, as well as the variability for each path (see Fig. 4), thus integrating the variability of wind conditions among days during the migration period. Calculations were made with the 'pathdistance' command on an ArcInfo Workstation 9.1.

\section{RESULTS}

\section{Tracking data}

In general, spatio-temporal patterns of the migratory episodes of each species were fairly similar among individuals, showing a general pattern overall, but also with some inter-individual variability. From the 8 Manx Puffinus puffinus shearwaters, the first bird started the portion of the analysed trajectory on 6 April and the last started on 1 May. Birds arrived at the end of the considered portion between 23 April and 5 May 2007. On average, trips were $10400 \mathrm{~km}$ long (SD = $1100)$, and lasted $20 \mathrm{~d}(\mathrm{SD}=4)$. In the case of the 20 transequatorial Cory's Calanectris diomedia shearwaters included in the analysis, dates of the origin and end of the analysed trajectory were more dispersed; the onset ranging from 24 November 2002 to 8 December and the end ranging from 3 to 29 December. On average, trips were $10000 \mathrm{~km}$ long (SD = 800) and lasted 22 d. Finally, Cape Verde C. edwardsii shearwaters showed a greater spatio-temporal cohesion. The 25 tracked shearwaters left the wintering grounds between 11 February and 5 March 2007 and arrived at the breeding colony between 26 February and 21 March 2007. On average, trips were $9100 \mathrm{~km}$ long $(\mathrm{SD}=1300)$ and lasted for $13 \mathrm{~d}(\mathrm{SD}=2)$ (Figs. 2 to 4$)$.

\section{Wind-mediated cost and path length}

In most cases, the cost of each path was strongly dependent on which day this cost was calculated. That is, the range of cost for each path could double or triple depending on the simulated departure day (Fig. 4). Median cost varied substantially depending on the length of the path, but this relationship was not uniform among species. In Manx shearwaters, neighbouring short paths (up to $8000 \mathrm{~km}$ ) showed disparate average costs (Fig. 4a). Longer paths were increasingly more costly, suggesting that wind assistance did not favour birds taking longer pathways. The estimated cost and the length of the observed synthesis path was 98860 cost units and $8890 \mathrm{~km}$, respectively; for the alternative synthesis path with the minimum cost, it was 87550 cost units and $7100 \mathrm{~km}$, respectively, whereas, for the shortest path, the cost was 105040 cost units and the distance was $7050 \mathrm{~km}$.

In Cory's shearwaters, shorter paths $(<8000 \mathrm{~km})$ were increasingly more costly, being up to $50 \%$ more costly than the lowest cost synthesis path (Fig. 4b). The estimated cost and the length of the observed synthesis path was 102630 cost units and $9730 \mathrm{~km}$, respectively; for the alternative synthesis path with the minimum cost, it was 90590 cost units and $11070 \mathrm{~km}$, respectively, whereas, for the shortest path, the cost was 141400 cost units and the distance was $6400 \mathrm{~km}$.

In Cape Verde shearwaters, the cost was more uniform regardless of the length of the path. Intermediate length paths (from 8000 to $11000 \mathrm{~km}$ ) showed slightly lower costs, but the range of the cost for each path was strongly dependent on the departure day (Fig. 4c). The estimated cost and the length of the observed synthesis path was 122830 cost units and $8840 \mathrm{~km}$, respectively; for the alternative synthesis path with the minimum cost, it was 109200 cost units and $10300 \mathrm{~km}$, respectively, whereas, for the shortest path, the cost was 121940 cost units and the distance was $6300 \mathrm{~km}$.

\section{DISCUSSION}

The trajectories analysed from Manx Puffinus puffinus, Cory's Calonectris diomedia and Cape Verde $C$. edwardsii shearwaters did not follow the shortest (great circle) trajectory between breeding and wintering areas, rather flyways were from 26 to $52 \%$ longer (Figs. 2 \& 4). This result confirms that transoceanic detours are common in long-distance-migrating seabirds. In terrestrial birds, detours are often related to refuelling needs, predator avoidance, or the need to circumvent ecological barriers (Alerstam 2001, Erni et al. 2005, Newton 2008). Although shearwaters do not have major predators at sea, the marine environment also presents potential ecological barriers, such as strong winds and oligotrophic waters. Indeed, refuelling needs could force shearwaters to take longer pathways around low-food-availability areas. Shorter pathways would cross oligotrophic waters in the centre of Atlantic gyres, which are poor in epipelagic fish and cephalopods. There is conflicting evidence on foraging behaviour during migration. Some studies show that shearwaters feed while migrating (Spear et al. 2007, Guilford et al. 2009). On the contrary, the speed of migration suggests that shearwaters do not usually stop over to refuel during migration, and depth loggers 
a

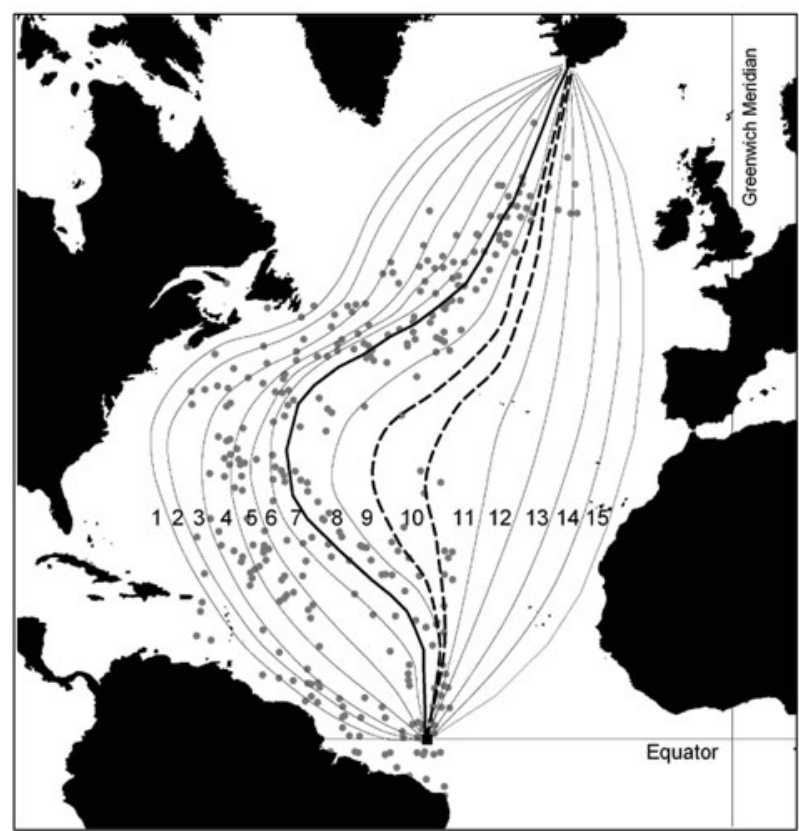

C

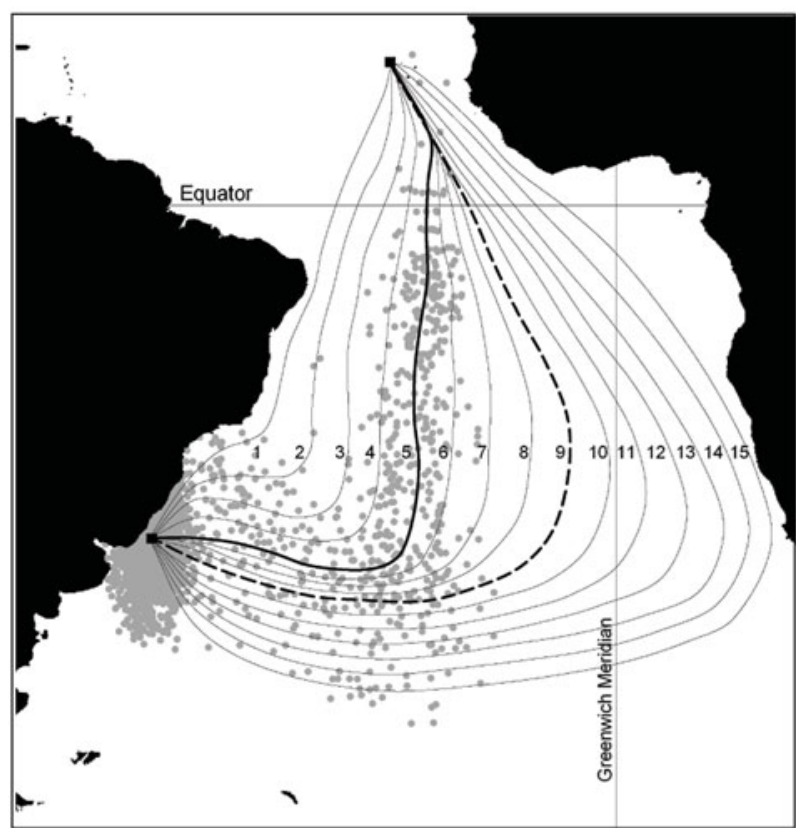

deployed on sooty shearwaters Puffinus griseus showed that birds do not generally dive during their transequatorial trips (Shaffer et al. 2006).

In seabirds, detours are probably related to an optimisation of time and energy in relation to differences in wind assistance. In fact, our results show that migration costs are strongly dependent on wind conditions. Wind-mediated costs on the most costly day ranged from being 25 to $150 \%$ more expensive than on the least costly day for a given pathway (Fig. 4), using simulated days of departure within the migration period defined by the tracked birds. Variability

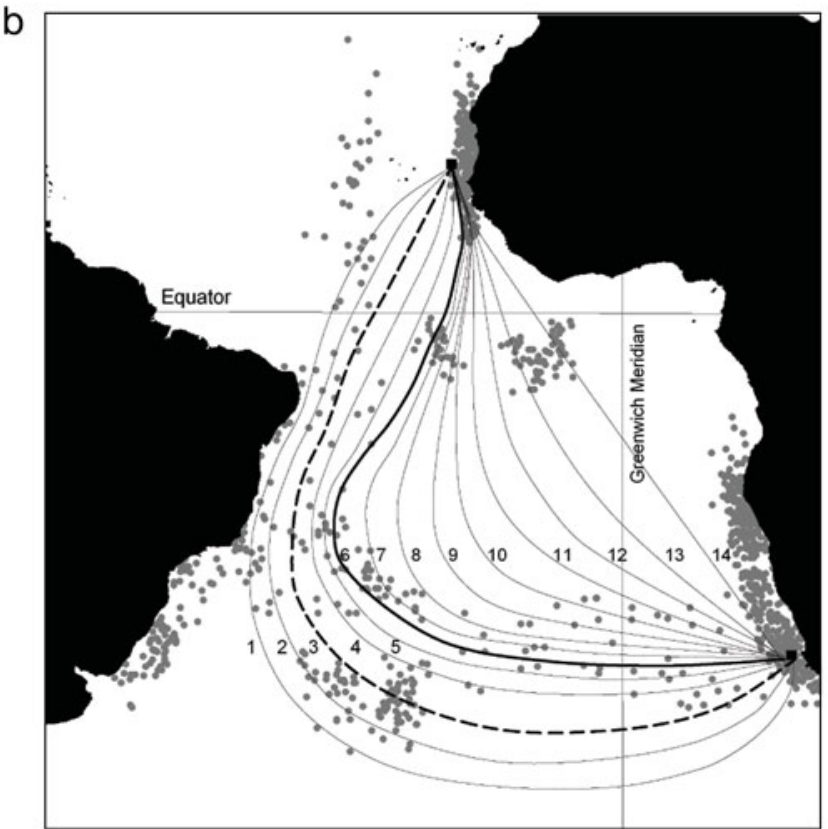

Fig. 2. Puffinus puffinus, Calonectris diomedia, C. edwardsii. Observed synthesis pathways used by shearwaters (solid line), minimum wind-mediated cost synthesis pathways (dashed lines) and similar alternative pathways (thin solid lines) for (a) the prenuptial migration of the Manx shearwater from 6 April to 5 May 2007, from the equator to Iceland; (b) the postnuptial migration of the Cory's shearwater from 24 November to 29 December 2002 from the Canary to the Benguela Currents; and (c) the prenuptial migration of the Cape Verde shearwater from 11 February to 21 March 2007 from the Brazil-Falklands Convergence to Cape Verde Island, tracked with geolocators. Tracked positions are also included as gray dots. Numbers correspond to the paths shown in Fig. 4.

in cost was also huge in pathways with very different lengths. For instance, among Cory's shearwaters, pathways varying between 8000 and $13000 \mathrm{~km}$ in length showed similar average costs, but each of them ranging from 80000 to 140000 cost units. These results confirm that wind conditions during the journey can have a strong impact on the cost of migrating, and therefore shearwaters should develop strategies to select optimal departure dates. In terrestrial birds, it has been shown that birds tend to depart with tailwinds, which help them to migrate faster and save some energy (Liechti \& Bruderer 1998, Akesson 
a

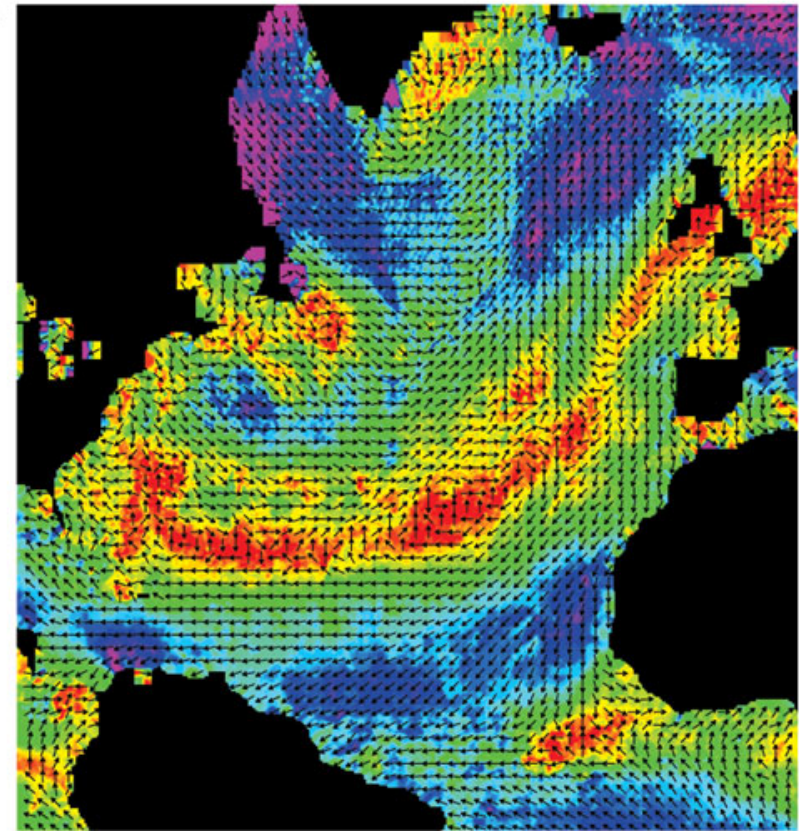

C

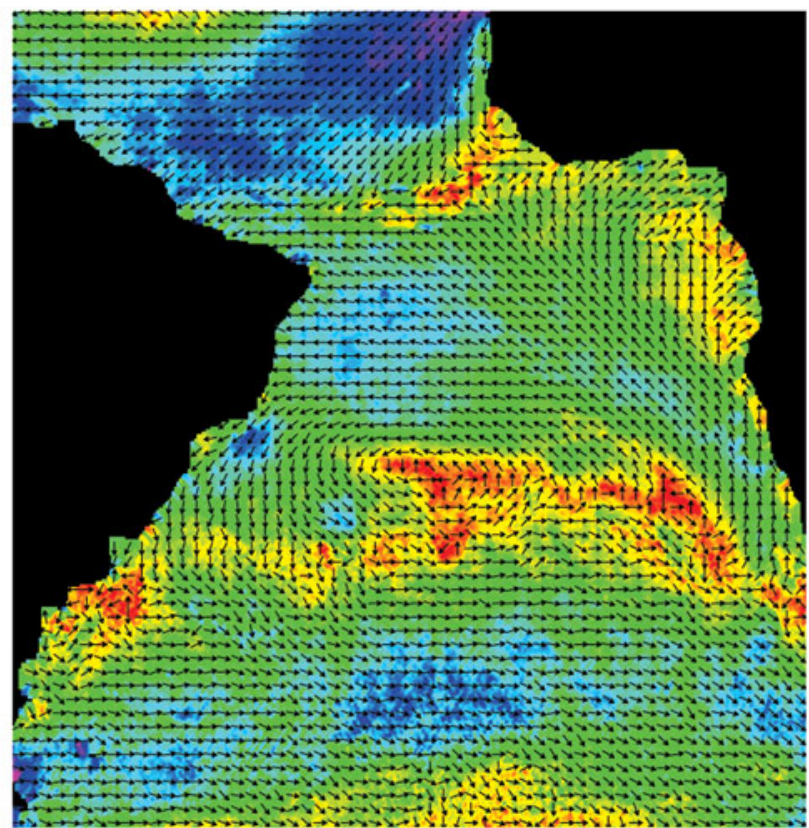

\& Hedenström 2000). Indeed, because pelagic seabirds cannot escape from the influence of unfavourable winds when travelling, coupling migration phenology with winds may be particularly critical. In this regard, it has been suggested that shearwaters may adjust the timing of crossing the equator to avoid the monsoon westerlies associated with the Atlantic intertropical convergence zone during summer months (Felicísimo et al. 2008).

The optimal migration pathway depends on how shearwaters seek to compromise between windmediated costs and travelling time. In general, when b

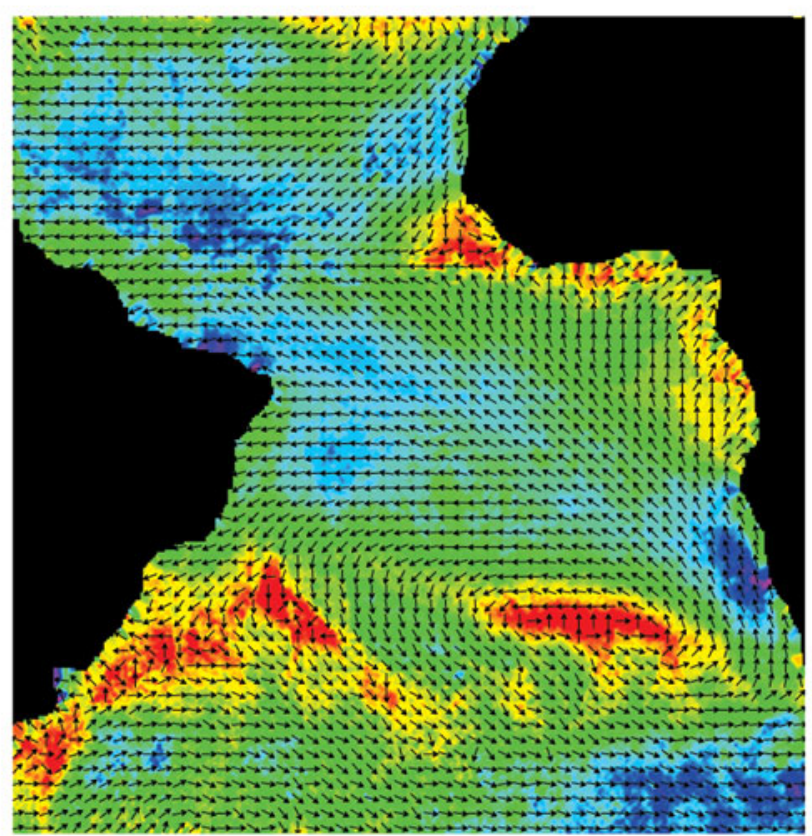

Fig. 3. Average wind strength and direction during the migration period in which shearwaters were tracked is shown for (a) the Manx, (b) the Cory's and (c) the Cape Verde shearwaters, calculations were made on daily wind conditions. Wind speed is colour coded from fuchsia $\left(0 \mathrm{~m} \mathrm{~s}^{-1}\right)$ to green $\left(6 \mathrm{~m} \mathrm{~s}^{-1}\right)$ to red $\left(\geq 15 \mathrm{~m} \mathrm{~s}^{-1}\right)$

the lowest cost (a synthesis derived from wind resistance models) and the shortest distance pathways between breeding and wintering areas differed, the observed synthesis path for the different shearwater species was relatively close to the lowest cost synthesis pathway (Figs. $2 \& 4$ ). Observed synthesis pathways in the 3 species were only about 12 to $13 \%$ more costly than the theoretically lowest cost synthesis pathway. In the Cory's and Cape Verde shearwaters, the observed synthesis pathways were 14 to $16 \%$ shorter than the lowest cost synthesis pathways, suggesting that the extra cost was somehow compen- 

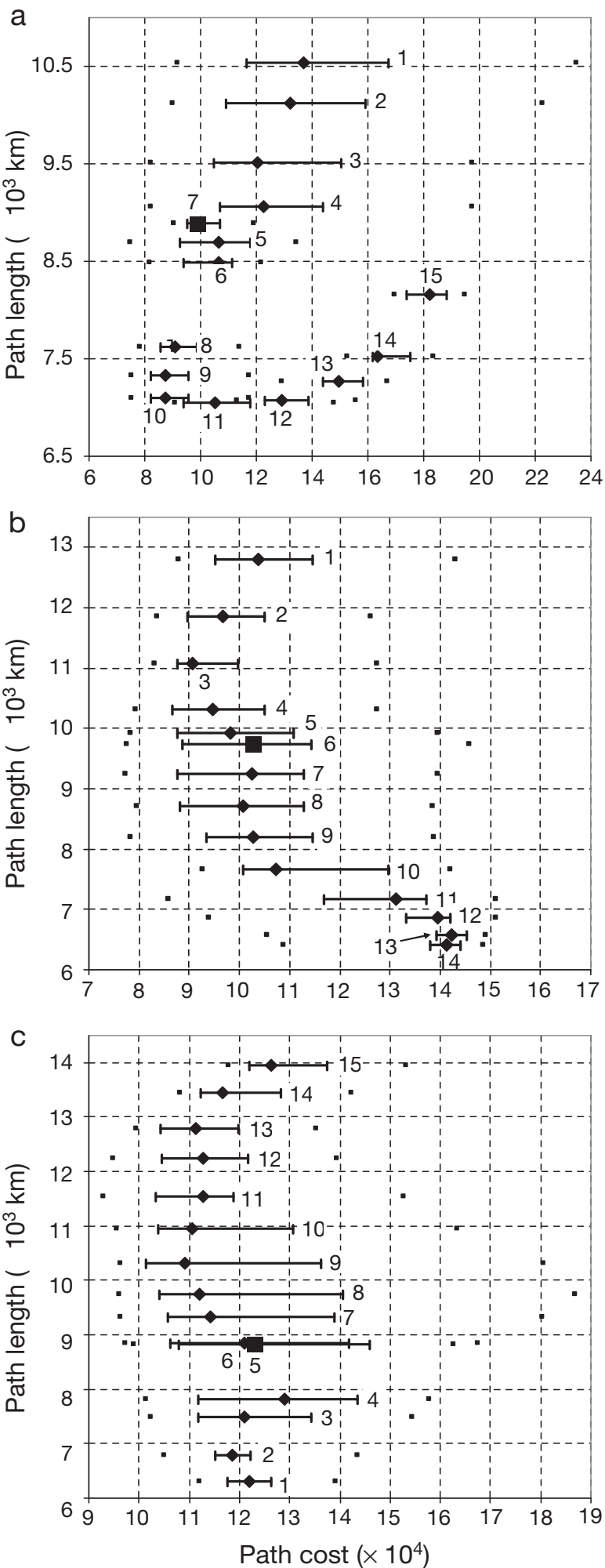

Fig. 4. Puffinus puffinus, Calonectris diomedia, C. edwardsii. Wind-mediated costs (arbitrary units) and path lengths $(\mathrm{km})$ of the trajectories shown in Fig. 2 for (a) Manx shearwaters, (b) Cory's shearwaters and (c) Cape Verde shearwaters. For each path, the cost was calculated every day within the migration period. Results are shown as median, quartile and range values. Numbers correspond to the paths shown in Fig. 2 sated by saving about $2 \mathrm{~d}$ of travelling time. In the case of the Manx shearwater, however, the observed path was not only $12 \%$ more costly, but also $25 \%$ longer. This opposite trend may be a consequence of Manx shearwater having greater wing-loading compared to Cory's or Cape Verde shearwaters. Manx shearwaters fly with more frequent flapping, much more energetically costly, which may force them to forage during migration, as revealed by a recent study (Guilford et al. 2009). Alternatively, this trend may result from the unpredictability shown by shorter pathways (Fig. 4a; path lengths from 7000 to 8000 $\mathrm{km})$. Manx shearwaters could certainly have taken from 10 to $25 \%$ shorter paths, with even lower costs. However, among shorter paths, trajectories of similar length show disparate costs (Fig. $4 \mathrm{a}$; trajectories 8 to 15), suggesting that shearwaters would face the high risk of expending up to double the cost. That is, disparate costs suggest more turbulent and unpredictable weather at the centre of an Atlantic gyre, perhaps deterring shearwaters from crossing it.

In some cases, the trade-off between time and cost in simulated pathways was apparently more optimal than that selected by the birds. For example, the cost of the average observed pathway in Cory's shearwaters was 102631 cost units and the length $9734 \mathrm{~km}$. However, simulated pathways up to $1500 \mathrm{~km}$ shorter showed similar wind-mediated costs, suggesting Cory's shearwaters may have saved about 2 or 3 travelling days. Similar conclusions could be drawn for the Cape Verde shearwater observed synthesis pathway. Discrepancies between optimal and observed synthesis pathways may result from the lack of reliable environmental cues for pathway choice, as well as the influence of prevailing winds on bird migration at an evolutionary scale. As we have shown, migration costs are strongly dependent on wind conditions, but wind patterns may be unpredictable or seabirds may not always have enough information during their migratory episodes to choose the lowest cost pathway. Even if birds have enough information, wind conditions in a single year may not be an adequate scale of study. Shearwaters can live for $>30 \mathrm{yr}$, and therefore pathway choice may depend on the experience gained over many years. Indeed, it has been shown that memory and culture may play an important role in shaping the foraging strategies of seabirds (Grémillet et al. 2004, Camphuysen \& Van de Meer 2005). Alternatively, pathways may just have been selected over generations, according to the consistency of wind patterns over the years. Largescale wind patterns in the Atlantic seem highly predictable, but whether the migratory routes shown in the present study are similar among years is still unknown. In this regard, long-term tracking studies and the analysis of migration pathways over several 
years in relation to the changing meteorological conditions would bring new insights into the understanding of the evolution of migration routes. Nevertheless, the fact that birds chose low cost pathways for the transoceanic trips of the 3 shearwater species analysed here suggest that winds are of decisive importance for the evolution of migration systems in seabirds.

Acknowledgements. We thank all the people who deployed and recovered geolocators and provided support in many different ways, in particular S. Martins, A. Rendall, P. López, L. F. Lopez-Jurado, E. Vendrell, T. Militão, P. Rodrigues, R. Ramos, P. Deane, G. Dell'Omo, P. Calabuig, L. Estévez, I. de Vicente, E. Gómez-Díaz, J. Navarro, I. A. Sigurdsson, R. Magnúsdóttir, A. M. Maul, V. Neves, J. Bried, X. Ruiz, D. Oro, M. Igual, L. Llorens, D. Briggs and J. P. Croxall; the NASA Ocean Wind Vector Science Team for making wind data available; Consejeria de Medio Ambiente del Cabildo de Gran Canaria, Secretaria Regional do Ambiente da Região Autónoma dos Açores, Gobern Balear, South Iceland Nature Centre, Direcção Geral do Ambiente and the Instituto Nacional de Investigação e Desenvolvimento Agrário from Cape Verde, for providing means and support. The comments of 5 anonymous referees greatly improved the first version of the manuscript. J.G-S. was supported by a contract of the Program Ramón y Cajal of the MEyC and by Fondos FEDER during fieldwork and analysis. Additional financial support was provided by the project CGL2007-60247/BOS and CGL200601315/BOS from Ministerio de Ciencia e Innovación and BIOCON04/099 from Fundación Banco Bilbao Vizcaya Argentaria.

\section{LITERATURE CITED}

Afanasyev V (2004) A miniature daylight level and activity data recorder for tracking animals over long periods. Mem Natl Inst Polar Res (Jpn) 58(Spec Issue):227-233

Åkesson S, Hedenström A (2000) Wind selectivity of migratory flight departures in birds. Behav Ecol Sociobiol 47 : $140-144$

Alerstam T (1979) Wind as selective agent in bird migration. Ornis Scand 10:76-93

Alerstam T (1990) Bird migration. Cambridge University Press, Cambridge

Alerstam T (2001) Detours in bird migration. J Theor Biol 209: $319-331$

Alerstam T, Lindström A (1990) Optimal bird migration: the relative importance of time, energy, and safety. In: Gwinner E (ed) Bird migration: physiology and ecophysiology. Springer-Verlag, Berlin

Alerstam T, Gudmundsson GA, Larsson B (1993) Flight tracks and speeds of Antarctic and Atlantic seabirds: radar and optical measurements. Philos Trans R Soc Lond B Biol Sci 340:55-67

Brooke M (1990) The Manx shearwater. Academic Press, London

Camphuysen CJ, Van de Meer J (2005) Wintering seabirds in West Africa: foraging hotspots off Western Sahara and Mauritania driven by upwelling and fisheries. Afr J Mar Sci 27:427-437

Camphuysen CJ, Van Der Meer J (2001) Pelagic distribution, moult and (sub-) specific status of Cory's shearwaters Calonectris /d./ diomedea/ borealis wintering off southern Africa. Mar Ornithol 29:89-96
Erni B, Liechti F, Bruderer B (2005) The role of wind in passerine autumn migration between Europe and Africa. Behav Ecol 16:732-740

Felicísimo AM, Muñoz J, González-Solís J (2008) Ocean surface winds drive dynamics of transoceanic aerial movements. PLoS One 3:e2928

> Furness RW, Bryant DM (1996) Effect of wind on field metabolic rates of breeding northern fulmars. Ecology 77 : 1181-1188

Gauthreaux SA Jr, Michi JE, Belser CG (2004) The temporal and spatial structure of the atmosphere and its influence on bird migration strategies. In: Greenberg R, Marra PP (eds) Birds of two worlds. The ecology and evolution of migration. The Johns Hopkins University Press, Baltimore, MD

González-Solís J, Croxall JP, Oro D, Ruiz X (2007) Transequatorial migration and mixing in the wintering areas of a pelagic seabird. Front Ecol Environ 5:297-301

Grémillet D, Kuntz G, Delbart F, Mellet M and others (2004) Linking the foraging performance of a marine predator with local prey abundance. Funct Ecol 18:793-801

Guilford T, Meade J, Willis J, Phillips RA and others (2009) Migration and stopover in a small pelagic seabird, the Manx shearwater Puffinus puffinus: insights from machine learning. Proc R Soc Lond B Biol Sci 276: 1215-1223

Houston AI (1998) Models of optimal avian migration: state, time and predation. J Avian Biol 29:395-404

Igual JM, Forero MG, Tavecchia G, González-Solís J and others (2005) Short-term effects of data-loggers on Cory's shearwater (Calonectris diomedea). Mar Biol 146:619-624

J. P. Laboratory (2001) QuikSCAT science data product. User's manual, Vers 2.2. JPL Document 18053, California Institute of Technology, Pasadena, CA

- Liechti F (2006) Birds: Blowin' by the wind? J Ornithol 147:202-211

> Liechti F, Bruderer B (1998) The relevance of wind for optimal migration theory. J Avian Biol 29:561-568

Murray MD, Nicholls DG, Butcher E, Moors PJ, Walker K, Elliot G (2003) How wandering albatrosses use weather systems to fly long distances. 3. The contribution of Antarctic LOWS to eastward, southward and northward flight. Emu 103:111-120

> Navarro J, González-Solís J (2009) Environmental determinants of foraging strategies in Cory's shearwaters Calonectris diomedea. Mar Ecol Prog Ser 378:259-267

Newton I (2008) The migration ecology of birds. Academic Press, Amsterdam

Nicholls DG, Murray MD, Butcher E, Moors P (1997) Weather systems determine the non-breeding distribution of wandering albatross over southern oceans. Emu 97:240-244

Pennycuick CJ (1982) The flight of petrels and albatrosses (Procellariiformes) observed in South Georgia and its vicinity. Philos Trans R Soc Lond B Biol Sci B300:75-106

Phillips RA, Silk JRD, Croxall JP, Afanasyev V, Briggs DR (2004) Accuracy of geolocation estimates for flying seabirds. Mar Ecol Prog Ser 266:265-272

> Richardson WJ (1990) Wind and orientation of migrating birds: a review. Experientia 46:416-425

> Rosén M, Hedenström A (2001) Testing predictions from flight mechanical theory: a case study of Cory's shearwater and Audouin's gull. Acta Ethol 3:135-140

Serventy DL (1953) Movements of pelagic seabirds in the Indo-Pacific region. Proc Natl Acad Sci USA 4:394-407

Shaffer SA, Tremblay Y, Weimerskirch H, Scott D and others (2006) Migratory shearwaters integrate oceanic resources across the Pacific Ocean in an endless summer. Proc Natl Acad Sci USA 103:12799-12802 
Spear LB, Ainley DG (1999) Migration routes of sooty shearwaters in the Pacific Ocean. Condor 101:205-218

Spear LB, Ainley DG, Walker WA (2007) Foraging dynamics of seabirds in the eastern tropical Pacific Ocean. Stud Avian Biol 35:i-x, 1-99

Spruzen FL, Woehler EJ (2002) The influence of synoptic weather patterns on the at sea behaviour of three species

Editorial responsibility: Scott Shaffer, Santa Cruz, California, USA of albatrosses. Polar Biol 25:296-302

> Vrugt JA, van Belle J, Bouten W (2007) Pareto front analysis of flight time and energy use in long-distance bird migration. J Avian Biol 38:432-442

> Weimerskirch H, Guionnet T, Martin J, Shaffer SA, Costa DP (2000) Fast and fuel efficient? Optimal use of wind by flying albatrosses. Proc R Soc Lond B Biol Sci 267:1869-1874

Submitted: November 20, 2008; Accepted: May 26, 2009

Proofs received from author(s): July 24, 2009 